\title{
Pendidikan Dwibahasa di Malaysia: Upaya Bahasa Melayu
}

\author{
Zuraini Ramli \\ Fakulti Bahasa dan Komunikasi, Universiti Pendidikan Sultan Idris \\ zuraini@fbk.upsi.edu.my
}

DOI: https://doi.org/10.37134/peradaban.vol14.2.2019

\begin{abstract}
ABSTRAK
Keupayaan bahasa Melayu sebagai bahasa ilmu telah terbukti sejak sekian lama dan tidak perlu diragui lagi. Makalah ini meneliti peranan dan kedudukan bahasa Melayu dalam bidang pendidikan, pada ketika Malaysia melaksanakan dasar bahasa Inggeris sebagai bahasa pengantar untuk mata pelajaran Sains dan Matematik. Kajian dijalankan secara kualitatif di dua buah sekolah menengah di negeri Melaka, melibatkan kaedah rakaman video dalam kelas, temu bual separa berstruktur dengan guru dan kumpulan pelajar terpilih, serta pemerhatian dalam kelas. Data dianalisis menggunakan perisian penganalisis kualitatif data Transana, melalui prosedur pengekodan. Dapatan kajian menunjukkan bahawa bahasa Melayu digunakan dalam majoriti aktiviti pengajaran dan pembelajaran yang dirakam, melibatkan interaksi formal dan tidak formal guru dan pelajar. Bahasa Inggeris pula, hanya digunakan dalam perbualan formal, apabila disertai oleh bahan-bahan sokongan seperti buku teks, video, dan nota di papan putih sahaja. Keterhadan penggunaan bahasa Inggeris menggambarkan bahawa bahasa tersebut tidak sesuai dijadikan bahasa pengantar dalam konteks pendidikan di sekolah di Malaysia. Dalam masa yang sama, bahasa Melayu dilihat berwibawa dan berkebolehan untuk mengungkapkan ilmu sains dan matematik, sama ada secara formal mahupun tidak formal.
\end{abstract}

Kata kunci: bahasa Melayu, sains, matematik, pendidikan dwibahasa, bahasa pengantar, Malaysia

\begin{abstract}
The ability of Malay language as a language of knowledge has been proven long ago. This article examines the role and position of Malay language in education, at the time when Malaysia was implementing the policy of English as the medium of instruction for Science and Mathematics. This qualitative research was done at two secondary schools in Melaka, which involved classroom video recording, semi-structured interview with the teachers and selected group of students, and classroom observation. The data was analyzed using a qualitative analysis software Transana, especially for generating and examining the coding procedure. The results show that Malay language was employed in most of the activities in the selected lessons, involving formal and informal teacher-students interaction. English on the other hand, was only used in formal transaction, when aided by text book, video, and notes on the board. The restricted used of English reflect the unsuitability of the language as a medium of instruction in schools in Malaysia. Meanwhile at the same time, the results highlighted the ability and versatility of Malay language as the language of knowledge, formal or informally.
\end{abstract}

Keywords: Malay language, science, mathematics, bilingual education, medium of instruction, Malaysia

\section{PENGENALAN}

Bahasa Melayu merupakan bahasa kebangsaan dan juga bahasa rasmi di Malaysia. Hal ini jelas diperuntukkan dalam Perkara 152 dalam Perlembagaan Malaysia, yang menetapkan bahawa bahasa 
Melayu wajib digunakan untuk semua urusan rasmi di peringkat kerajaan persekutuan, kerajaan negeri dan juga badan berkanun. Sebagai bahasa kebangsaan dan bahasa rasmi, seharusnya bahasa Melayu merupakan bahasa pengantar utama dalam sistem pendidikan di Malaysia. Tugas ini sudah digalas oleh bahasa Melayu semenjak negara mencapai kemerdekaan pada tahun 1957 lagi. Peranan bahasa Melayu menjadi semakin mantap apabila dijadikan bahasa pengantar di semua sekolah rendah dan menengah pada tahun 1982. Pada tahun 1983 pula, bahasa Melayu mengorak langkah yang lebih jauh apabila mula digunakan sebagai bahasa pengantar di peringkat universiti awam (Alis, 2006).

Walau bagaimanapun, sehingga kini, kedudukan bahasa Melayu sebagai bahasa pengantar utama dalam sistem pendidikan di Malaysia sering goyah dengan berlakunya gejala-gejala yang boleh menyebabkan pengurangan fungsi dan peminggiran bahasa tersebut. Menurut Awang Sariyan (2005; 263), pengurangan fungsi dan peminggiran bahasa Melayu dalam bidang-bidang yang telah ditetapkan oleh Perlembagaan Persekutuan, Akta Bahasa Kebangsaan, Akta Pendidikan, dan Akta Dewan Bahasa dan Pustaka secara langsung akan menjejaskan martabat bahasa Melayu sebagai salah satu tonggak pembinaan negara. Antara polisi yang menyumbang pengurangan fungsi dan peminggiran bahasa Melayu dalam sistem pendidikan di Malaysia ialah Pengajaran dan Pembelajaran Sains dan Matematik dalam bahasa Inggeris (PPSMI) yang dilaksanakan selama sembilan tahun, iaitu dari 2003 hingga 2012. Menerusi PPSMI, kerajaan berhasrat untuk menyediakan generasi Malaysia agar berkemampuan untuk bersaing dalam era globalisasi, serta untuk menguasai ilmu dan ledakan informasi dalam sains dan teknologi yang didominasi bahasa Inggeris (Sopia, David, Ong \& Lai, 2009). Namun demikian, setelah lapan tahun dilaksanakan, polisi tersebut ternyata tidak berupaya menyediakan perubahan sebagaimana yang diharapkan. Kajian menunjukkan hanya peratusan kecil guru menggunakan bahasa Inggeris dalam pengajaran dan pembelajaran Sains dan Matematik. Selain itu, berlaku kemerosotan dalam pencapaian pelajar sekolah rendah dalam kedua-dua subjek tersebut. Juga diakui oleh kerajaan bahawa pelajar menghadapi kesukaran menggunakan bahasa Inggeris sebagai bahasa pengantar (Zuraini, 2014).

Matlamat utama penulisan makalah ini adalah untuk meneliti peranan dan kedudukan bahasa Melayu dalam PPSMI, iaitu sewaktu bahasa Inggeris menjadi bahasa pengantar bagi mata pelajaran Sains dan Matematik. Dalam konteks negara Malaysia, bahasa Melayu merupakan bahasa pertama kaum Melayu, manakala umumnya menjadi bahasa kedua atau ketiga kepada bangsa lain seperti Cina dan India. Sebaliknya, bahasa Inggeris merupakan bahasa kedua atau ketiga kepada sebahagian besar warganegara Malaysia. Dengan status sebagai bahasa pertama atau kedua kepada kebanyakan rakyat Malaysia, sudah pasti bahasa Melayu menjadi bahasa yang penting dalam situasi pembelajaran sewaktu PPSMI berlangsung. Dengan meneliti peranan bahasa Melayu dalam konteks PPSMI, diharapkan makalah ini berupaya menyerlahkan kemampuan sebenar bahasa Melayu sebagai bahasa ilmu, di samping menegaskan perlunya bahasa rasmi menjadi bahasa pengantar dalam sistem pendidikan sesebuah negara.

\section{KAEDAH DAN SAMPEL KAJIAN}

Makalah ini memberi tumpuan kepada peranan dan kedudukan bahasa Melayu dalam pengajaran dan pembelajaran (PdP) dwibahasa di Malaysia, iaitu ketika bahasa Inggeris digunakan sebagai bahasa pengantar untuk mata pelajaran Sains dan Matematik di semua peringkat sekolah. Data diperoleh daripada dua buah sekolah menengah di negeri Melaka, melibatkan dua kelas Matematik dan dua kelas Sains di setiap sekolah. Pelajar tingkatan dua dipilih sebagai sampel dalam kajian ini kerana mereka merupakan kumpulan pertama yang belajar sains dan matematik dalam bahasa Inggeris bermula daripada darjah satu di sekolah rendah, iaitu pada tahun 2003. Oleh sebab kebanyakan sekolah menengah di Malaysia mengamalkan pembahagian kelas mengikut pencapaian akademik, dua kelas baik dan dua kelas sederhana daripada setiap sekolah dipilih untuk menyertai kajian ini. Pemilihan pelajar yang memiliki perbezaan tahap pencapaian akademik bertujuan untuk mendapatkan kepelbagaian kemahiran bahasa Inggeris dalam kalangan mereka. Dua buah sekolah menengah di negeri Melaka telah dipilih, iaitu 
Sekolah B (Bandar) dan Sekolah LB (Luar Bandar). Jadual 1 dan Jadual 2 memaparkan gambaran keseluru

\section{SEKOLAH LB}

Matematik

\section{Guru: Zila Rahim ${ }^{1}$}

Kecekapan Bahasa Inggeris Guru: Sederhana

Bilangan Pelajar: 32 (Melayu)

Topik: Statistics \& Frequency

Bahasa Yang Digunakan Guru: Bahasa Melayu dan Inggeris

Bahasa Yang Digunakan Pelajar: Bahasa Melayu dan Inggeris

\section{Guru: Bo Yang}

Kecekapan Bahasa Inggeris Guru: Sederhana

Bilangan Pelajar: 32 (Melayu, Cina dan India)

Topik: Reflection \& Surface Area

Bahasa Yang Digunakan Guru: Bahasa Melayu dan

Inggeris

Bahasa Yang Digunakan Pelajar: Bahasa Melayu dan Inggeris

\section{Sains}

Guru: Kalsom Karim

Kecekapan Bahasa Inggeris Guru: Sederhana

Bilangan Pelajar: 32 (Melayu)

Topik: Force \& Measurement of Force

Bahasa Yang Digunakan Guru: Bahasa Melayu dan Inggeris

Bahasa Yang Digunakan Pelajar: Bahasa

Melayu dan Inggeris

\section{Guru: Hasnah Ahmad}

Kecekapan Bahasa Inggeris Guru: Sederhana

Bilangan Pelajar: 35 (Melayu, Cina dan India)

Topik: Stability

Bahasa Yang Digunakan Guru: Bahasa Melayu dan Inggeris

Bahasa Yang Digunakan Pelajar: Bahasa Melayu, Inggeris, Mandarin dan Tamil

han sampel kajian di kedua-

dua buah sekolah (Zuraini ,2016).

JADUA

L 1:

Karektor

Guru,

Pelajar

dan

Kelas di

Sekolah

LB

\footnotetext{
${ }^{1}$ Semua nama yang digunakan ialah nama samaran.
} 


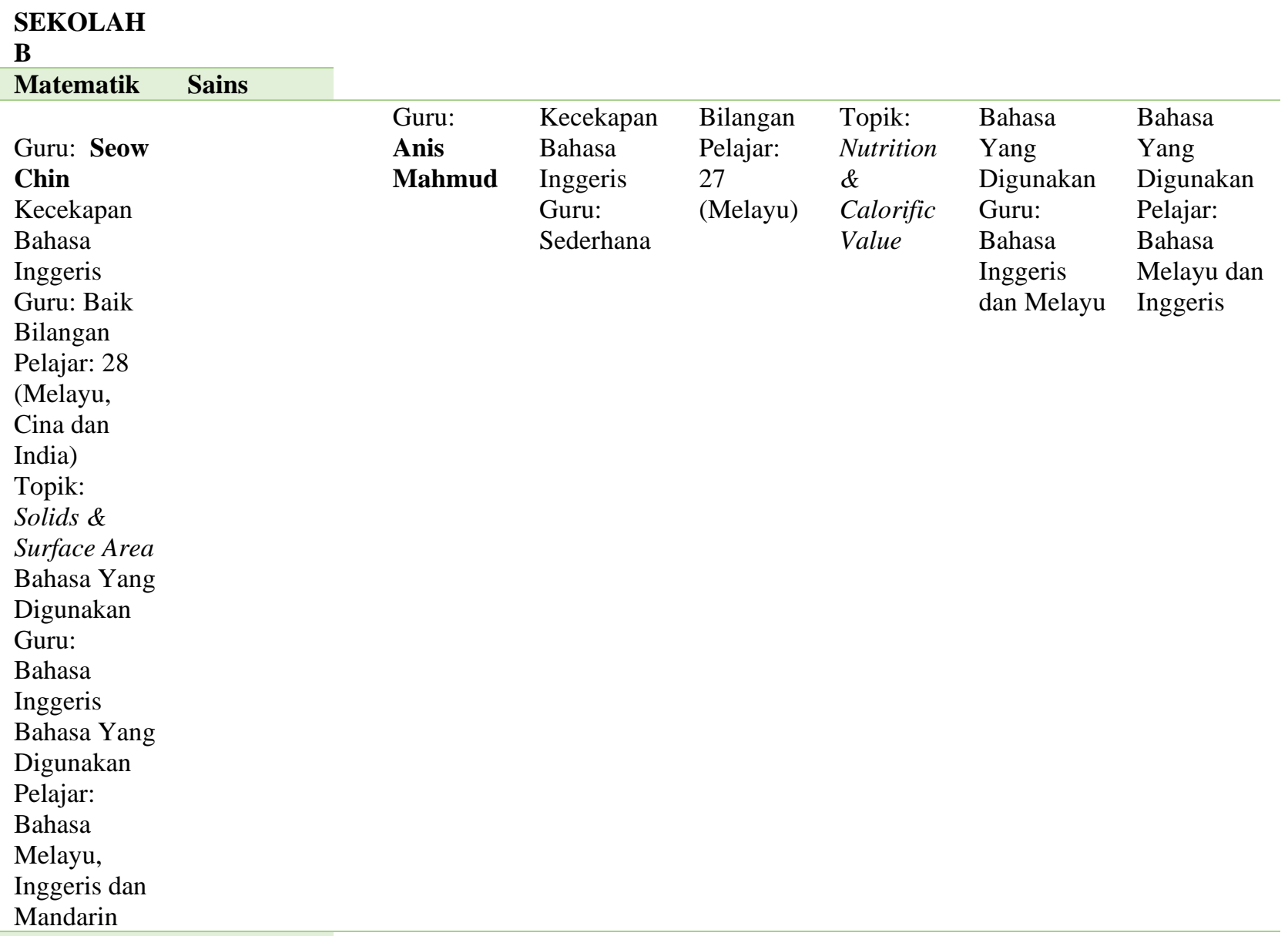

\section{Guru: Guru:}

Normah Ali Beng Hong

Kecekapan Kecekapan

Bahasa Bahasa

Inggeris Inggeris

Guru: Lemah Guru:

ke Sederhana Sederhana

Bilangan Bilangan

Pelajar: 29 Pelajar: 29

(Melayu, (Melayu,

Cina dan Cina dan

India) India)

Topik: Topik:

Rotation \& Support

Linear System \&

Equation Stability

Bahasa Yang Bahasa

Digunakan Yang

Guru: Digunakan

Bahasa Guru:

Melayu. Bahasa

Bahasa Inggeris,

Inggeris Melayu dan

hanya untuk Mandarin 


$\begin{array}{ll}\text { istilah } & \text { Bahasa } \\ \text { khusus } & \text { Yang } \\ \text { sahaja } & \text { Digunakan } \\ \text { Bahasa Yang } & \text { Pelajar: } \\ \text { Digunakan } & \text { Bahasa } \\ \text { Pelajar: } & \text { Melayu, } \\ \text { Bahasa } & \text { Inggeris } \\ \text { Melayu, } & \text { dan } \\ \text { Inggeris dan } & \text { Mandarin } \\ \text { Mandarin } & \end{array}$

Rakaman video dalam kelas merupakan data utama yang digunakan dalam kajian ini. Semua guru yang terlibat, dan sekumpulan pelajar yang terdiri daripada dua hingga lima orang pelajar, dirakam menggunakan dua buah kamera video. Video pertama merakam guru dan keseluruhan kelas, manakala video kedua difokuskan kepada satu kumpulan pelajar yang dipilih berdasarkan cadangan guru. Semua guru dan kumpulan pelajar yang dipilih juga ditemu bual menerusi sesi "temu bual berdasarkan rangsangan video" (video-stimulated recall interview) sebagai usaha untuk memperoleh perspektif mereka tentang penggunaan bahasa dan tujuannya, serta strategi pengajaran dan pembelajaran. Nota daripada pemerhatian dalam kelas membekalkan konteks tambahan untuk setiap pengajaran dan pembelajaran yang dirakam, selain menjadi rujukan tambahan kepada data yang telah ditranskrip (Zuraini Ramli, 2016).

Dalam makalah ini, perbincangan berfokus kepada penggunaan bahasa guru dan murid sepanjang PdP berlangsung. Untuk tujuan tersebut, perbincangan akan dibuat berdasarkan gambar rajah Series Keyword Sequence Map yang memaparkan penggunaan bahasa dalam PdP terpilih, mengikut empat jenis percakapan guru, iaitu "Percakapan Berkaitan Isi Kandungan" (Content-related Talk), "Percakapan berkaitan Organisasi Kelas" (Organizational Talk), "Percakapan Berkaitan Disiplin" (Disciplinary Talk), dan "Percakapan Berkaitan Hal Tidak Formal" (Informal Talk). Jadual 3 memaparkan huraian kepada kategori pengekodan yang dibuat untuk kajian ini.

JADUAL 3: Huraian Kategori Pengekodan

\begin{tabular}{lll}
\hline \multicolumn{1}{c}{ KATEGORI } & \multicolumn{1}{c}{ SUBKATEGORI } & \multicolumn{1}{c}{ HURAIAN } \\
\hline & $\begin{array}{l}\text { 1. Tugasan Seluruh Kelas (Whole } \\
\text { class work) }\end{array}$ & $\begin{array}{l}\text { Pengurusan kelas yang melibatkan keseluruhan kelas atau } \\
\text { seluruh pelajar melakukan tugas atau aktiviti yang serupa. }\end{array}$ \\
\cline { 2 - 3 } $\begin{array}{l}\text { 2. Tugasan Individu (Individual } \\
\text { Tork) }\end{array}$ & $\begin{array}{l}\text { Pengurusan kelas yang melibatkan setiap pelajar melakukan } \\
\text { tugasan secara individu. }\end{array}$ \\
\hline $\begin{array}{l}\text { KELAS } \\
\text { (CLASSROOM }\end{array}$ & $\begin{array}{l}\text { 3. Tugasan Berkumpulan (Group } \\
\text { Pengurusan kelas yang melibatkan setiap pelajar melakukan }\end{array}$ \\
\hline
\end{tabular}




\begin{tabular}{|c|c|c|}
\hline ORGANISATION) & work) & tugas atau aktiviti secara berkumpulan. \\
\hline \multirow{3}{*}{$\begin{array}{l}\text { INTERAKSI } \\
\text { (INTERACTION) }\end{array}$} & $\begin{array}{l}\text { 1. Pengajaran Langsung } \\
\text { (Expository) }\end{array}$ & $\begin{array}{l}\text { Interaksi yang melibatkan guru bercakap dan pelajar mendengar } \\
\text { dengan senyap. }\end{array}$ \\
\hline & 2. Dimulakan Guru (Teacher Led) & $\begin{array}{l}\text { Interaksi yang melibatkan guru bertanya soalan berdasarkan } \\
\text { topik yang dibincangkan. }\end{array}$ \\
\hline & 3. Dimulakan Pelajar (Student Led) & $\begin{array}{l}\text { Interaksi yang melibatkan pelajar bertanya soalan berdasarkan } \\
\text { topik yang dibincangkan. }\end{array}$ \\
\hline \multirow{4}{*}{$\begin{array}{l}\text { BAHASA } \\
\text { (LANGUAGE) }\end{array}$} & Bahasa Inggeris (English) & $\begin{array}{l}\text { Guru menggunakan bahasa Inggeris untuk berinteraksi dengan } \\
\text { pelajar. }\end{array}$ \\
\hline & Bahasa Melayu (Malay) & $\begin{array}{l}\text { Guru menggunakan bahasa Melayu untuk berinteraksi dengan } \\
\text { pelajar. }\end{array}$ \\
\hline & Campuran (Mixture) & $\begin{array}{l}\text { Guru menggunakan bahasa campuran untuk berinteraksi dengan } \\
\text { pelajar. }\end{array}$ \\
\hline & Bahasa Lain (Others) & $\begin{array}{l}\text { Guru menggunakan bahasa selain daripada bahasa Melayu dan } \\
\text { Inggeris (seperti bahasa Mandarin) untuk berinteraksi dengan } \\
\text { pelajar. }\end{array}$ \\
\hline \multirow{4}{*}{$\begin{array}{l}\text { PERCAKAPAN } \\
\text { (TALK) }\end{array}$} & $\begin{array}{l}\text { 1. Berkaitan Isi Kandungan } \\
\text { (Content Related) }\end{array}$ & $\begin{array}{l}\text { Percakapan guru tentang isi kandungan atau kemahiran yang } \\
\text { perlu diajar, seperti mengulang kaji topik yang dibincangkan } \\
\text { dalam pelajaran lepas, memperkenalkan topik baharu, } \\
\text { menghuraikan topik, atau meringkaskan sesuatu topik }\end{array}$ \\
\hline & $\begin{array}{l}\text { 2. Berkaitan Organisasi } \\
\text { (Organizational) }\end{array}$ & $\begin{array}{l}\text { Percakapan guru untuk mengendalikan aktiviti dan penglibatan } \\
\text { pelajar, menetapkan sesuatu aktiviti, memberikan arahan umum, } \\
\text { membentuk kumpulan, mengatur kedudukan kumpulan; } \\
\text { mengurus masa dan ruang, memberitahu pelajar tentang aktiviti } \\
\text { berikutnya, menguruskan peralihan. }\end{array}$ \\
\hline & 3. Berkaitan Disiplin (Disciplinary) & $\begin{array}{l}\text { Mendisiplinkan pelajar, pengurusan tingkah laku, kelas dan } \\
\text { kawalan pelajar. }\end{array}$ \\
\hline & $\begin{array}{l}\text { 4. Berkaitan Hal Tidak Formal } \\
\text { (Informal) }\end{array}$ & Percakapan berkaitan hal tidak formal bersama pelajar. \\
\hline
\end{tabular}

Gambar rajah Series Keyword Sequence Map merupakan gambar rajah yang dijana secara automatik oleh perisian Transana sewaktu proses pengekodan dilakukan. Gambar rajah tersebut memaparkan analisis secara terperinci maklumat penggunaan bahasa dalam sesuatu PdP, berdasarkan pada kategori kod yang disenaraikan dalam Jadual 3. Terdapat empat kategori utama yang dikod, iaitu Pengurusan Kelas, Interaksi, Bahasa, dan Percakapan. Setiap kategori diperincikan kepada subkategori yang lebih kecil.

Bagi tujuan analisis aspek penggunaan bahasa, hanya lima PdP dipilih untuk dibincangkan dalam artikel ini, dan fokus perbincangan hanya menyentuh aspek bahasa yang digunakan bagi kategori percakapan guru dan pelajar sahaja. Kategori Interaksi dan Pengurusan Kelas tidak dibincangkan dengan terperinci, hanya disentuh sekiranya berkaitan dengan perbincangan. Gambar rajah Series Keyword Sequence Map yang dipilih untuk dibincangkan ialah gambar rajah Series Keyword Sequence Map bagi PdP Kalsom, Zila, Bo, Beng, dan Normah.

\section{PdP KALSOM}

Rajah 1 memaparkan Series Keyword Sequence Map PdP Kalsom untuk mata pelajaran Sains di Sekolah LB. Kalsom merupakan seorang guru Sains, yang berpengalaman mengajar selama empat tahun. Beliau merupakan graduan lulusan universiti tempatan, mengkhusus dalam bidang Matematik dan Biologi. Sebagaimana yang dipaparkan dalam Jadual 1, Kalsom menilai penguasaan bahasa Inggerisnya sebagai sederhana, iaitu bagus dalam pemahaman, tetapi kurang cekap dalam kemahiran bertutur dalam bahasa Inggeris. Topik yang dibincangkan pada hari itu ialah Force, melibatkan kelas baik yang terdiri daripada semua pelajar Melayu. 

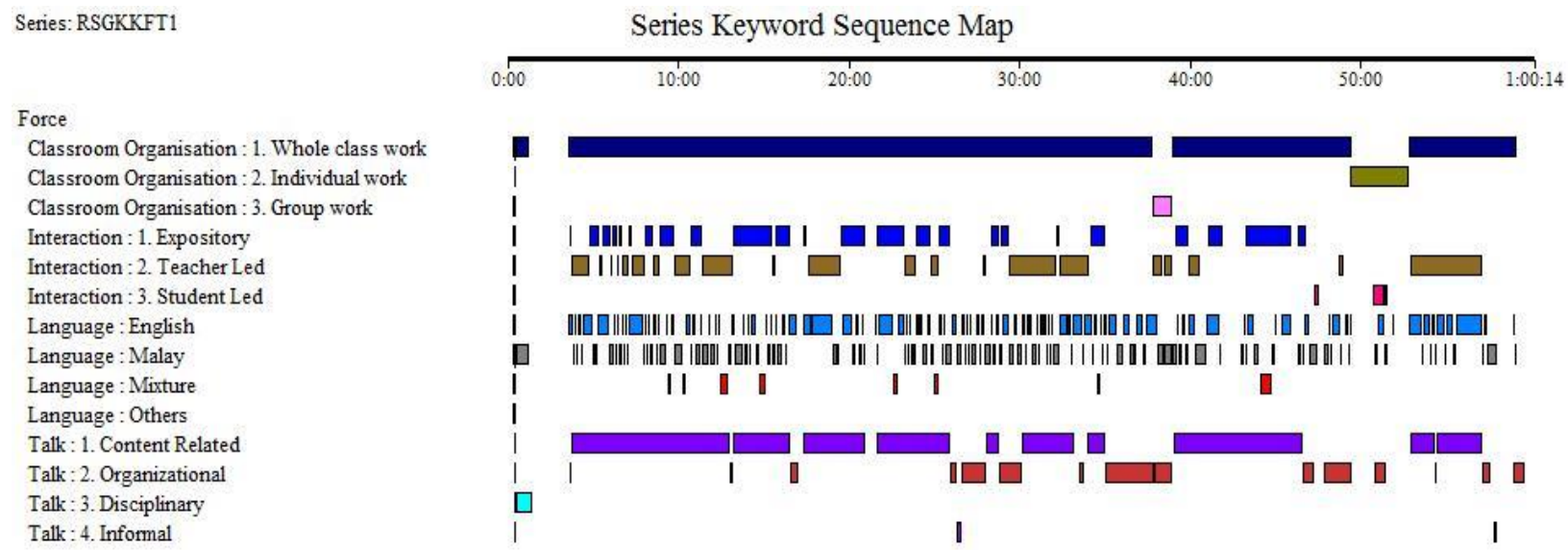

RAJAH 1 Series Keyword Sequence MapKalsom

Berdasarkan Rajah 1, didapati Kalsom menggunakan kedua-dua bahasa, iaitu bahasa Inggeris dan bahasa Melayu dalam pengajarannya. Bahasa Melayu digunakan pada permulaan PdP, iaitu ketika Kalsom mengatur tempat duduk para pelajarnya mengikut kumpulan masing-masing. Percakapan formal bermula beberapa minit kemudian, dengan segmen yang panjang yang kebanyakannya percakapan "Berkaitan Isi Kandungan". Bahasa yang digunakan pada permulaan segmen ini ialah bahasa Inggeris. Bagaimanapun, Kalsom mula menggunakan bahasa Melayu apabila beliau cuba menterjemahkan huraian yang dinyatakan dalam bahasa Inggeris. Bermula daripada detik itu, Kalsom dilihat menggunakan kedua-dua bahasa Inggeris dan Melayu secara berselang-seli. Hal ini berlaku kerana Kalsom menterjemah hampir setiap perkataan bahasa Inggeris yang diucapkannya. Perubahan bahasa daripada bahasa Inggeris ke Melayu dan sebaliknya, berlaku dengan kerap dan cepat dalam setiap ayat yang dilafazkannya sehingga sukar untuk mengaitkan bahasa mana yang lebih dominan untuk jenis percakapan tertentu. Bahasa Melayu digunakan khususnya dalam tugasan berkumpulan, dan ketika guru memberikan contoh-contoh atau mengaitkan perbincangan dengan pengalaman seharian pelajar. Selain itu, Kalsom juga menggunakan bahasa campuran Inggeris dan Melayu, kebanyakannya sewaktu bercakap tentang isi kandungan pelajaran.

\section{PdP ZILA}

Dalam Rajah 2, diperlihatkan Series Keyword Sequence Map PdP Zila, seorang lagi guru di sekolah LB yang mengajar mata pelajaran Matematik. Beliau merupakan responden termuda, dengan pengalaman mengajar kurang daripada setahun. Beliau juga merasakan keupayaan berbahasa Inggerisnya sederhana. Topik yang dibincangkan dalam PdP tersebut ialah Statistics. 

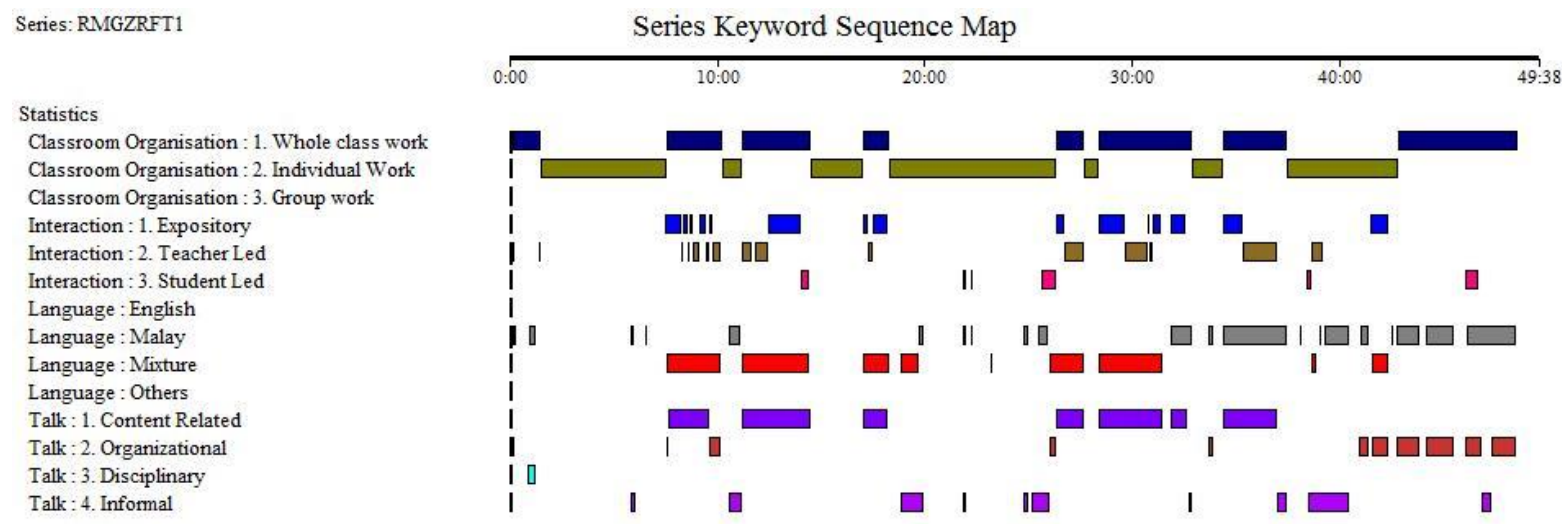

RAJAH 2 Series Keyword Sequence Map Zila

Rajah 2 menunjukkan bahawa Zila hanya menggunakan dua bahasa sahaja, iaitu bahasa Melayu dan campuran bahasa Melayu dan Inggeris. Bahasa Inggeris sepenuhnya tidak digunakan langsung dalam PdP ini, hanya muncul dalam bahasa campuran semata-mata. Kebanyakan perkataan bahasa Inggeris diucapkan berdasarkan kepada bahan bertulis yang tersedia dalam PdP tersebut, sama ada daripada buku teks ataupun yang tertulis di papan putih. Bahasa campuran banyak digunakan dari awal hingga pertengahan PdP, yang selari dengan jenis percakapan "Berkaitan Isi Kandungan". Bahasa Melayu pula banyak digunakan dari pertengahan hingga ke akhir kelas tersebut, yang selari dengan percakapan berkaitan "Organisasi Kelas" dan "Hal Tidak Formal".

\section{PdP BO}

Rajah 3 merujuk Series Keyword Sequence Map PdP Bo, guru Matematik di Sekolah LB. Bo merupakan guru matematik berbangsa Cina, berpengalaman selama 14 tahun mengajar dengan pengkhususan dalam bidang Matematik. Beliau juga merasakan penguasaan bahasa Inggerisnya sederhana. PdP ini adalah berkaitan topik "Surface Area" melibatkan pelajar kelas sederhana. Dari aspek bahasa, Bo menggunakan semua jenis bahasa yang terdapat dalam kategori bahasa, iaitu bahasa Inggeris, bahasa Melayu, bahasa campuran, dan bahasa lain (Mandarin). Terdapat pola yang agak sekata dari segi penggunaan bahasa dengan kategori percakapan guru, iaitu Bo banyak menggunakan bahasa Inggeris untuk percakapan "Berkaitan Isi Kandungan", manakala bahasa Melayu dan bahasa campuran banyak digunakan untuk percakapan berkaitan "Organisasi Kelas" dan "Disiplin". Bahasa lain, iaitu bahasa Mandarin, hanya digunakan sekali sahaja dalam PdP tersebut, untuk percakapan "Berkaitan Isi Kandungan". Umumnya, Rajah 3 memaparkan bahawa pada peringkat awal PdP, Bo banyak menggunakan bahasa Inggeris untuk memperkenalkan dan menghuraikan topik untuk PdP tersebut. Bagaimanapun, apabila lebih banyak interaksi dilakukan dengan pelajar, Bo mula menggunakan bahasa Melayu. Bahasa Melayu juga digunakan hampir sepenuhnya sewaktu aktiviti kerja berkumpulan, iaitu ketika Bo bergerak dari satu kumpulan ke satu kumpulan untuk membuat huraian dan penjelasan lanjut kepada pelajar. Selain itu, bahasa Melayu dilihat digunakan hampir sepenuhnya untuk kategori percakapan "Berkaitan Organisasi", "Disiplin" dan "Hal Tidak Formal", yang berlangsung pada separuh akhir masa PdP tersebut. 


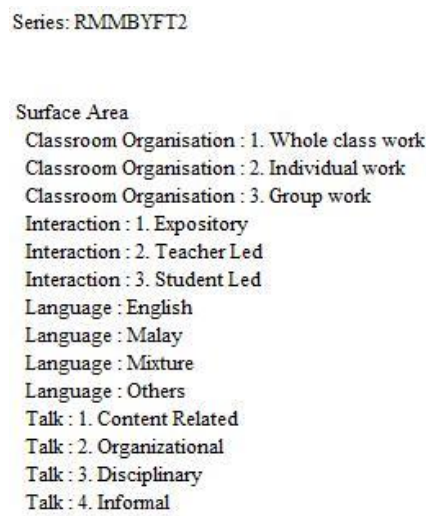

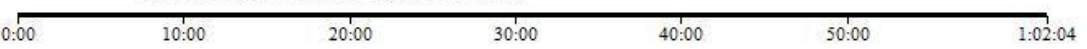

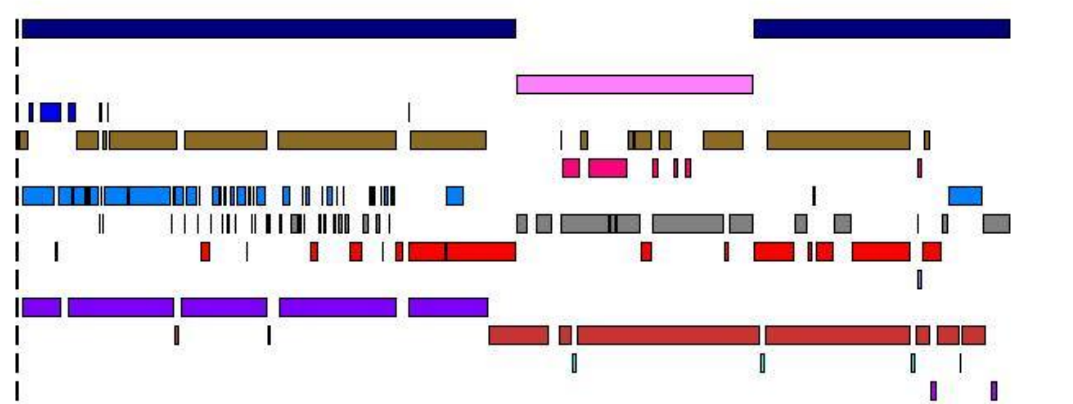

RAJAH 3: Series Keyword Sequence Map Bo

\section{PdP BENG}

Series: USMBHFT2

Stability

Classroom Organisation : 1 . Whole class work Classroom Organisation : 2 . Individual work Classroom Organisation : 3. Group work

Interaction : 1 . Expository

Interaction : 2 . Teacher Led

Interaction : 3 . Student Led

Language : English

Language : Malay

Language : Mixture

Language : Others

Talk: 1 . Content Related

Talk : 2 . Organizational

Talk : 3 . Disciplinary

Talk : 4 . Informal

\begin{tabular}{l}
\multicolumn{5}{l}{ Series Keyword Sequence Map } \\
$0: 00$ \\
$10: 00$
\end{tabular}

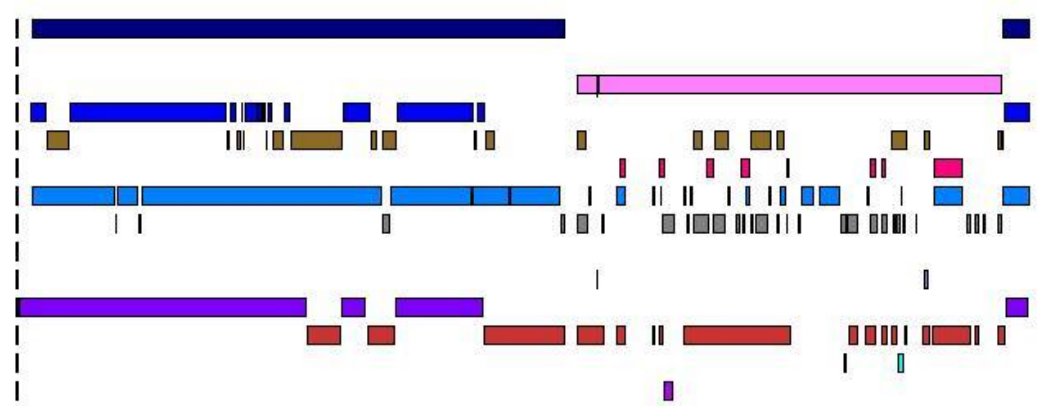

RAJAH 4: Series Keyword Sequence Map Beng

Rajah 4 memaparkan Series Keyword Sequence Map PdP Beng yang merupakan guru berpengalaman untuk mata pelajaran Sains di Sekolah B. Beliau berbangsa Cina,satu-satunya guru lelaki yang menjadi responden dalam kajian ini. Beliau yang berpengalaman selama 20 tahun mengajar di sekolah menengah berpendapat penguasaan bahasa Inggerisnya pada tahap sederhana. Secara keseluruhannya, Beng menggunakan bahasa Inggeris, bahasa Melayu, dan bahasa lain (Mandarin) dalam pengajarannya. Bahasa Inggeris digunakan hampir sepenuhnya dalam separuh pertama PdP, kebanyakannya berkaitan dengan percakapan "Berkaitan Isi Kandungan" dan sedikit "Berkaitan Organisasi". Perlu dinyatakan bahawa pada kebanyakan masa dalam separuh masa pertama PdP tersebut, Beng banyak merujuk buku teks Sains yang ditulis dalam bahasa Inggeris. Berikutnya, dalam separuh masa kedua PdP, Beng mula menukar bahasanya kepada bahasa Melayu apabila percakapannya banyak "Berkaitan Organisasi". Lebih banyak penggunaan bahasa Melayu dan Inggeris pada sebahagian akhir PdP, serta terdapat dua insiden Beng menggunakan bahasa Mandarin. Dapat dilihat bahawa untuk percakapan yang lebih formal, melibatkan perbincangan "Berkaitan Isi Kandungan", bahasa Inggeris digunakan sepenuhnya. Namun demikian, 
untuk percakapan "Berkaitan Organisasi" yang memerlukan Beng membuat lebih banyak perbualan dengan pelajarnya, bahasa Melayu menjadi pilihan. Hal ini lebih ketara dalam aktiviti kerja kumpulan, apabila pelajar perlu banyak berbincang dan berinteraksi sama ada dengan guru mahupun sesama mereka.

\section{PdP NORMAH}

Rajah 5 menunjukkan Series Keyword Sequence Map PdP Normah. Beliau merupakan guru Matematik di Sekolah B dengan tiga tahun pengalaman mengajar. Normah merupakan graduan universiti tempatan yang mengkhusus dalam bidang Biologi. Topik yang dibincangkan ialah Linear Equation, melibatkan pelajar daripada kelas sederhana. Dari segi bahasa, Normah menggunakan hampir sepenuhnya bahasa Melayu dalam PdP. Bahasa Inggeris hanya digunakan untuk mengungkapkan istilah matematik yang biasa seperti times dan equal, khususnya sewaktu beliau membimbing pelajar bukan Melayu untuk menyelesaikan masalah matematik yang diberikan.
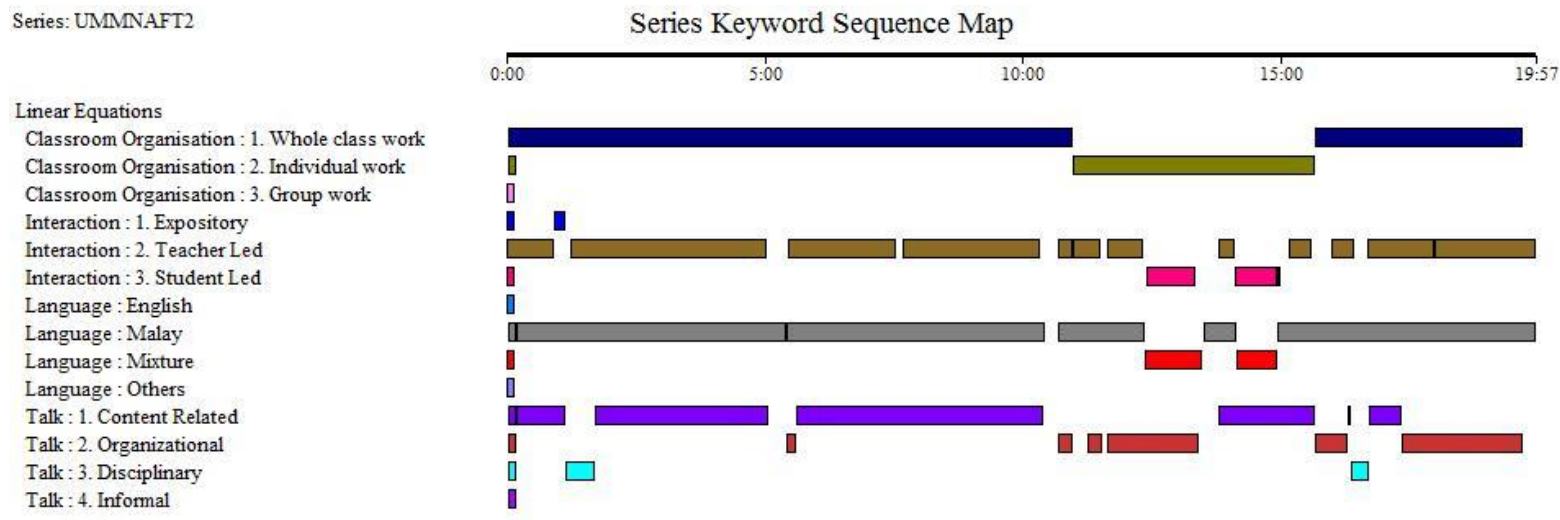

RAJAH 5: Series Keyword Sequence Map Normah

\section{PERBINCANGAN}

Melihat data yang dibincangkan sebelum ini, didapati bahawa semua guru menggunakan bahasa Inggeris dan bahasa Melayu, serta sedikit bahasa Mandarin dalam pengajaran mereka. Dalam kebanyakan PdP, bahasa Inggeris sering digunakan untuk percakapan "Berkaitan Kandungan", khususnya dalam PdP Kalsom, Beng, dan Bo. Bagaimanapun, percakapan "Berkaitan Organisasi" kebanyakannya menggunakan bahasa Melayu. Selain itu, tiada ditemui penggunaan bahasa Inggeris untuk percakapan "Berkaitan Disiplin" dan "Hal Tidak Formal", melainkan semuanya berlangsung dalam bahasa Melayu.

Daripada keempat-empat kategori percakapan guru, jelas dilihat bahawa bahasa Inggeris sering digunakan untuk percakapan berkaitan isi kandungan, yang kebanyakannya berlangsung pada sebahagian masa pertama sesuatu PdP. Hal ini dilihat berkait rapat dengan sumber berbahasa Inggeris yang tersedia di dalam kelas, seperti buku teks, nota di papan putih, dan video. Sebaliknya, bahasa Melayu selalu digunakan untuk kategori percakapan yang lain, iaitu berkaitan organisasi kelas, disiplin, dan hal tidak formal. Selain itu, guru-guru lebih cenderung untuk menggunakan bahasa Melayu sewaktu berinteraksi dengan pelajar mereka, khususnya ketika aktiviti kerja kumpulan. Bukan itu sahaja, bahasa Melayu juga menjadi pilihan guru untuk melakukan perbincangan yang lebih mendalam daripada huraian yang disediakan dalam buku teks atau nota mereka, terhadap sesuatu topik yang dibincangkan. 
Situasi-situasi di atas memperlihatkan bahawa sebagai bahasa pengantar, bahasa Inggeris hanya digunakan dalam bentuk formal, dengan sokongan sumber yang ada di sekeliling guru. Penggunaannya terhad kepada nota dan buku teks yang selalunya dibaca dengan kuat oleh guru pada bahagian awal sesuatu PdP. Walau bagaimanapun, apabila keperluan terhadap bahasa menjadi lebih tinggi dan kompleks, khususnya untuk membuat huraian yang lebih mendalam, atau mengaitkan sesuatu perkara dengan pengalaman harian pelajar, kebanyakan guru beralih kepada bahasa Melayu. Huraian yang dibuat dalam bahasa Melayu sering dilihat penyelamat kepada pelajar, membantu mereka untuk memahami sesuatu topik itu dengan lebih tepat dan mendalam.

\section{KESIMPULAN}

Perbincangan di atas membuktikan dua perkara utama yang diperoleh dalam PdP Sains dan Matematik sewaktu PPSMI, yang dianalisis dalam kajian ini. Pertama, polisi penggunaan bahasa Inggeris sebagai bahasa pengantar mata pelajaran Sains dan Matematik dapat dilaksanakan hanya dengan penggunaan bahasa Inggeris yang minimal dan terhad. Bahasa Melayu lebih banyak digunakan untuk mengungkapkan hal-hal yang lebih kompleks untuk difahami dengan lebih mudah oleh pelajar. Kedua, situasi ini menggambarkan bahawa, bahasa Melayu masih digunakan dengan dominan sebagai bahasa perantaraan antara guru dengan murid dalam PdP ketika itu. Hal ini jelas menujukkan bahawa bahasa Melayu amat berupaya untuk mengungkapkan ilmu berkaitan sains dan matematik, bahkan ilmu berkaitan apa-apa bidang sekalipun.

\section{RUJUKAN}

Awang Sariyan. (2005). Membitarakan bahasa dan budaya Melayu dalam konteks peneguhan tamadun negara dalam Suara Pejuang Bahasa. Abdul Rahim Bakar dan Awang Sariyan (Ed.). Kuala Lumpur: Persatuan Linguistik Malaysia.

Alis Puteh.(2006). Language and nation building: A study of the language medium policy in Malaysia. Petaling Jaya: Strategic Information and Research Development Centre.

Sopia Md Yassin, David Marsh, Ong Eng Tek, \& Lai Ying Ying (2009). Learners' perceptions towards the teaching of science through English in Malaysia: A quantitative analysis. International CLIL Research Journal, $1(2), 54-69$.

Zuraini Ramli. (2014). Teaching and Learning Mathematics and Science in a Second or Third Language. (Disertasi Doktor Falsafah yang tidak diterbitkan). Deakin University, Australia.

Zuraini Ramli. (2016). Kepelbagaian modaliti dalam pengajaran dan pembelajaran dwibahasa. Jurnal Pendeta, Jilid 7,156-169. 